\title{
Identidade molecular dos fitoplasmas associados aos enfezamentos do tomateiro e da berinjela com base na análise do gene $16 \mathrm{~S}$ rDNA
}

\author{
Ana Paula de Oliveira Amaral Mello, Ivan Paulo Bedendo, Luís Eduardo Aranha de Camargo
}

Setor de Fitopatologia ESALQ/USP, Av Pádua Dias 11, CEP 13418-900 Piracicaba, SP.

Autor para correspondência: Ivan P. Bedendo - ipbedend@esalq.usp.br

Data de chegada: 28/07/2005. Aceito para publicação em: 30/10/2006.

\section{RESUMO}

Amaral Mello, A.P.O.; Bedendo, I.P.; Camargo, L.E.A. Identidade molecular dos fitoplasmas associados aos enfezamentos do tomateiro e da berinjela com base na análise do gene 16S rDNA. Summa Phytopathologica, v.33, n.3, p.258-263, 2007.

Doenças de hortaliças de ocorrência no território brasileiro e em outras áreas do mundo têm sido associadas a diversos fitoplasmas. $\mathrm{Na}$ região de Piracicaba-SP e Bragança Paulista-SP, em plantas de tomate e berinjela foram observados sintomas típicos de enfezamento caracterizados por porte reduzido, clorose foliar, superbrotamento de ramos, desenvolvimento anormal do cálice, encurtamento de entre-nós, redução no tamanho de folhas, flores e frutos. Através de duplo PCR, utilizando os iniciadores R16 mF1/mR2 e R16 F2n/ $\mathrm{R} 2$, fragmentos de DNA de 1,2 $\mathrm{kb}$ foram amplificados de amostras sintomáticas, demonstrando a presença de fitoplasma nos tecidos das plantas. O uso de iniciadores específicos demonstrou que estes fitoplasmas eram afiliados ao grupo 16SrIII. Análises de RFLP, usando as enzimas de restrição $A l u \mathrm{I}, H p a \mathrm{II}, K p n \mathrm{I}, M b o \mathrm{I}, M s e \mathrm{I}$ e
RsaI confirmaram que os fitoplasmas detectados eram representantes do grupo 16 SrIII. Os fragmentos de DNA amplificados foram clonados em Escherichia coli, sequenciados e comparados, por homologia de seqüência, entre si e com outros fitoplasmas do grupo 16SrIII. Um índice de similaridade de seqüência acima de $95 \%$ foi encontrado quando seqüências dos fitoplasmas detectados em tomate e berinjela foram comparadas com aquelas de outros representantes do grupo 16SrIII. Um índice de 98-99\% foi obtido quando seqüências dos fitoplasmas encontrados em tomate e berinjela foram comparadas entre si. Estes resultados evidenciaram que o enfezamento do tomateiro e da berinjela podem estar associados a um mesmo fitoplasma, com base na análise de seqüências do gene do $16 \mathrm{~S}$ rDNA.

Palavras-chave adicionais: Mollicutes, amarelos, cálice gigante

\section{ABSTRACT}

Amaral Mello, A.P.O.; Bedendo, I.P.; Camargo, L.E.A. Molecular identity of the phytoplasma associated to stunting of tomato and eggplant on the basis of analyses of the 16s rDNA. Summa Phytopathologica, v.33, n.3, p.258-263, 2007.

Vegetable diseases occurring in the Brazilian territory and around the world have been associated with various phytoplasmas. In the region of Piracicaba-SP and Bragança-SP, in eggplant and tomato plants typical symptoms of stunting characterized by reduced canopy, leaf yellowing, proliferation of shoots, calix malformation, shortening internodes, reduced size of leaves, flowers and fruits were observed. In nested PCR with primers R16 mF1/mR2 e R16 $\mathrm{F} 2 \mathrm{n} / \mathrm{R} 2$, fragments of $1.2 \mathrm{~kb}$ in size were amplified from symptomatic samples demonstrating the presence of phytoplasmas in plant tissues. By using especific primers pairs it was demonstrated that the phytoplasmas were affiliated to group 16SrIII. RFLP analysis using the restriction enzymes AluI, HpaII,
$K p n I, M b o I, M s e I$, and RsaI confirmed that the phytoplasmas were representatives of group 16SrIII. Amplified DNA fragments were cloned in Escherichia coli, sequenced and compared by sequence similarities among themselves and with sequences belonging to phytoplasmas of group 16SrIII. Sequence similarities greater than $95 \%$ were found when the phytoplamas detected in tomato and eggplant were compared to the representatives of group 16SrIII. Values of 98-99\% were obtained when sequences of phytoplasmas found in tomato and eggplant were compared among themselves. The results evidenced that tomato and eggplant stunting were associated with the same phytoplasma based upon the sequencing of the $16 \mathrm{~S}$ rDNA gene.

Additional Keywords: Mollicutes, yellows, giant calix

Fitoplasmas são procariotos patogênicos a plantas, habitantes de floema, não cultiváveis em meio de cultura e naturalmente transmitidos por cigarrinhas (7). Os avanços da biotecnologia possibilitaram maior conhecimento destes microrganismos e permitiram a obtenção de oligonucleotídeos usados em PCR, para a detecção de fitoplasmas associados a doenças de plantas (13). A técnica de RFLP (Restriction Fragment Lenght Polymorphism), que consiste em analisar os padrões de digestão de DNAs gerados por enzimas de restrição, tem sido adotada internacionalmente, desde o início dos anos noventa, para fins de identificação e classificação de fitoplasmas (16). Atualmente, 
têm sido reconhecidos quatorze grupos de fitoplasmas e diversos subgrupos, sendo que para cada grupo se adotou um fitoplasma típico como referência (18) Uma das vantagens atribuída à técnica de RFLP é demonstrar a ocorrência de diferentes fitoplasmas numa mesma espécie vegetal ou relacionar fitoplasmas similares que ocorrem em espécies vegetais diferentes (1). Este tipo de informação pode contribuir para um maior entendimento sobre a epidemiologia da doença.

O sequenciamento do gene 16S rDNA também tem sido bastante utilizado para o estabelecimento de relações filogenéticas entre fitoplasmas, através da homologia de suas seqüências nucleotídicas $(11,22)$. Este tipo de estudo pode levar a uma maior compreensão sobre os mecanismos de patogenicidade do organismo, sua evolução, expressão de genes de resistência da planta às infecções e mecanismos de transmissão por insetos vetores (19).

No Brasil, uma ampla diversidade de gêneros e espécies vegetais são afetadas por doenças associadas aos fitoplasmas. Dentre as espécies cultivadas, estes fitopatógenos estão associados a diversas doenças de hortaliças, entre elas a berinjela e o tomateiro (15). As doenças associadas a fitoplasmas em berinjela e tomateiro são conhecidas por diversos nomes como superbrotamento, enfezamento, cálice gigante, folha pequena e outros, porém quando os sintomas são descritos observa-se que estes termos podem ser usados indistintamente para se referir à mesma doença.

A presença de fitoplasmas associados ao enfezamento de plantas de tomate e berinjela é conhecida há algum tempo em diversos países como Estados Unidos (6, 9), Índia $(26,28)$, Irã (24) e Israel (29). Mais recentemente, a identificação em nível molecular tem mostrado a ocorrência de diversidade de fitoplasmas associados aos enfezamentos do tomateiro. Nos Estados Unidos, um fitoplasma associado ao cálice gigante foi identificado como um representante do grupo 16SrI (16). No oriente médio um fitoplasma do grupo 16SrVI foi detectado em plantas de tomate com proliferação de ramos laterais, cálice gigante e virescência (2). Num levantamento realizado em cultivos comerciais de tomate em 1999 e 2000, na região central da Itália, foram identificados fitoplasmas pertencentes aos grupos $16 \mathrm{SrI}, 16 \mathrm{SrIII}, 16 \mathrm{SrV}$ e $16 \mathrm{SrXII}$ (25). Estes relatos comprovaram que fitoplasmas distintos podem induzir sintomas semelhantes numa mesma espécie vegetal.

No Brasil, na década de 60, fitoplasmas foram associados a plantas de tomate exibindo sintomas de superbrotamento de ramos, enfezamento, clorose, redução no tamanho de folhas e cálice gigante $(14,23)$. Trinta anos depois, no Distrito Federal, fitoplasmas foram detectados em plantas de berinjela exibindo os mesmos sintomas (5). Estes trabalhos se constituíram nos primeiros relatos sobre a ocorrência de fitoplasmas em berinjela e tomateiro no país, porém nenhum estudo foi conduzido, na época, quanto à classificação do fitopatógeno detectado. Na década de 90, no entanto, isolados encontrados em berinjela com sintomas de cálice gigante e superbrotamento, provenientes do Distrito Federal e de São Paulo foram identificados em nível molecular como membros do grupo 16SrIII (4).

No ano de 2002, plantas de tomate da região de Bragança Paulista (SP) e plantas de berinjela cultivadas em Piracicaba (SP) e Bragança Paulista (SP) exibindo sintomas típicos de fitoplasma foram alvos de estudo do presente trabalho. Estes sintomas se caracterizavam, em ambas as espécies vegetais, por porte reduzido da planta, clorose foliar acentuada, superbrotamento de ramos, desenvolvimento anormal do cálice, encurtamento de entre-nós, folhas, flores e frutos de tamanho reduzido, ou seja, sintomas típicos de enfezamento. O objetivo foi constatar a presença de fitoplasmas associados aos sintomas, bem como identificar por métodos moleculares estes fitoplasmas, e demonstrar o grau de identidade genética existente entre eles, com base no gene 16S rDNA.

\section{MATERIAL E MÉTODOS}

\section{Amostras de plantas de tomate e berinjela}

Folhas de plantas sintomáticas e assintomáticas de tomate e berinjela foram amostradas em áreas de cultivo situadas na região de Bragança Paulista (SP) e de Piracicaba (SP). As amostras de berinjela e tomate coletadas em Bragança Paulista foram identificadas por EB02 (enfezamento da berinjela) e ET02 (enfezamento do tomateiro) e as amostras de berinjela coletadas em Piracicaba foram identificadas por EB01.

\section{Detecção de fitoplasmas: extração de DNA total e condições de PCR}

A extração de DNA total foi feita a partir de material foliar (16) Para detecção de fitoplasma foi feita a amplificação da região do DNA genômico correspondente ao $16 \mathrm{~S}$ rDNA. Iniciadores ("primers") universais para fitoplasmas representados por R16 mF2 (5'cat gca agt cga acg a 3') / mR1 (5'ctt aac ccc aat cat cga c 3') e R16 F2n (5' gaa acg act gct aag act gg 3') R16 R2 (5' tga cgg gcg gtg tgt aca aac ccc g 3') (10) foram empregados em duplo PCR. Amostra de DNA proveniente de planta de chuchu, comprovadamente infectada por fitoplasma, foi usada como padrão positivo. Para os padrões negativos foram usados água e DNA total extraído de plantas assintomáticas. As reações de PCR foram processadas de acordo com protocolo apropriado (16). O termociclador foi programado para $1 \mathrm{~min}$ a $94{ }^{\circ} \mathrm{C}$, seguido de 35 ciclos, usando as seguintes etapas: $1 \mathrm{~min}$ a $94^{\circ} \mathrm{C}, 2$ min a $50{ }^{\circ} \mathrm{C}$ e 3 min a $72{ }^{\circ} \mathrm{C}$ e uma extensão final de 7 min a $72{ }^{\circ} \mathrm{C}$.

Todos os produtos de re-amplificação foram analisados através de eletroforese em gel de agarose (1\%), o qual foi submetido à coloração em brometo de etídeo, sendo a visualização das bandas feita em transiluminador sob luz ultravioleta. O marcador molecular utilizado foi $1 \mathrm{~kb}$ ladder (Life Technologies).

\section{Identificação de fitoplasmas por PCR}

Os fitoplasmas detectados nas amostras EB01, EB02 e ET02 foram submetidos a duplo PCR. Os produtos de amplificação da primeira reação de PCR, conduzida com par de iniciadores R16 $\mathrm{mF} 2 / \mathrm{mR} 1$, foram diluídos (1:50) em água destilada deionizada e submetidos à re-amplificação utilizando-se os pares de iniciadores específicos para fitoplasmas dos grupos 16SrI [R16(I)F1 (5' taa aag acc tag caa tag g 3') / /R16(I)R1 (5' caa tcc gaa ctg aga ctg t 3')], 16SrIII [R16(III)F2 (5' aag agt gga aaa act ccc 3') / R16(III)R1 (5' tcc gaa ctg aga ttg a $\left.\left.3^{\prime}\right)\right]$ e $16 \mathrm{SrV}\left[\mathrm{R} 16(\mathrm{~V}) \mathrm{F} 15^{\prime}\right.$ tta aaa aga ctt ctt cgg 3') / R16(V)R1 (5' ttc aat ccg tac tga gac tac c 3')] (17). As condições de PCR e de eletroforese foram idênticas àquelas descritas para detecção de fitoplasmas.

\section{Identificação de fitoplasmas por análise de RFLP}

As seqüências amplificadas pelo duplo PCR com iniciadores universais foram analisadas através de digestão com enzimas de restrição. Uma alíquota de $4 \mathrm{~mL}$ de cada produto de PCR foi digerida, separadamente, por diferentes endonucleases, seguindo as instruções do fabricante, por um período de $30 \mathrm{~h}$ a $36^{\circ} \mathrm{C}$. As enzimas AluI, HpaII, KpnI, MseI, RsaI e MboI foram usadas nas análises de RFLP. 
Os produtos da digestão enzimática foram separados por eletroforese em gel de poliacrilamida (4,5\%), sendo o gel corado em brometo de etídeo e os fragmentos de DNA gerados foram visualizados em transiluminador sob luz ultravioleta. O marcador de peso molecular utilizado foi o $\phi X 174 \mathrm{RFHaeIII}$ (Life Technologies). O perfil eletroforético de cada fitoplasma foi comparado aos padrões existentes na literatura $(4,8,18,21)$ e com base nestes resultados foi feita a identificação dos fitoplasmas, classificando-os em um dos 15 atuais grupos reconhecidos.

\section{Clonagem, sequenciamento e análise filogenética}

Os produtos do duplo PCR provenientes das amostras EB01, EB02 e ET02 foram clonados em Escherichia coli usando o kit de clonagem pGEM T Easy Vector System I (Promega), de acordo com as instruções do fabricante. Foram seqüenciados cinco clones com fragmentos de $1,2 \mathrm{~kb}$ para cada uma das amostras representadas por EB01, EB02 e ET02, em sequenciador automático ABI Prism 377 (PE Applied Biosystems). Iniciadores M13 foram usados nas reações de PCR. O alinhamento e análise comparativa das seqüências, bem como a análise putativa dos sítios de restrição, foram feitos através do Programa DNA Sequencer 3.0 (Gene Code Corporation). Cada fragmento foi sequenciado pelo menos duas vezes para maior confiabilidade dos dados. Também foram determinados os índices de similaridade entre as seqüências. Assim sendo, foi possível comparar o nível de identidade genética existente entre os fitoplasmas de cada amostra de tomate e berinjela.

\section{RESULTADOS E DISCUSSÃO}

\section{Detecção de fitoplasmas}

Com base na amplificação do fragmento genômico correspondente ao $16 \mathrm{~S}$ rDNA, através dos iniciadores $\mathrm{R} 16 \mathrm{mF} 2$ / $\mathrm{mR} 1$ e re-amplificação deste fragmento pelo par R16 F2n/R2, ficou demonstrada a presença de fitoplasmas em tecidos de plantas sintomáticas de tomate e berinjela (dados não apresentados). Estas amplificações, obtidas pelo uso de duplo PCR, foram visualizadas na forma de bandas de aproximadamente $1,2 \mathrm{~kb}$, a partir de DNA extraído das amostras EB01, EB02 e ET02 originárias de plantas com enfezamento. Bandas de 1,2kb também foram observadas para amostra de chuchu usada como padrão positivo. Nenhuma amplificação ocorreu para os padrões negativos representados pela água e por DNA total extraído de plantas de tomate e berinjela assintomáticas.

\section{Identificação de fitoplasmas por PCR com primers específicos}

A amplificação de DNAs dos fitoplasmas feita através de duplo PCR, com iniciadores específicos para os diferentes grupos, mostrou a ocorrência de uma banda de $0,8 \mathrm{~kb}$ visualizada no gel de agarose, demonstrando que fitoplasmas pertencentes ao grupo 16SrIII (grupo do fitoplasma do "X-disease") estavam presentes tanto nas amostras de tomate como de berinjela (Figura 1). Ausência de bandas foi constatada nos PCRs conduzidos com os iniciadores específicos para identificação de fitoplasmas dos grupos $16 \mathrm{SrI}$ e $16 \mathrm{SrV}$, embora produtos de amplificação tenham sido constatados nas reações correspondentes aos controles positivos de cada grupo (Figura 1, colunas 1,2,3). O uso de iniciadores específicos para identificação de fitoplasmas dos grupos 16SRI, 16SRIII e $16 \mathrm{SrV}$ foi feita, pois a maioria dos fitoplasmas se enquadram nos grupos 16SRI e 16SrIII, além da disponibilidade de iniciadores para estes grupos.

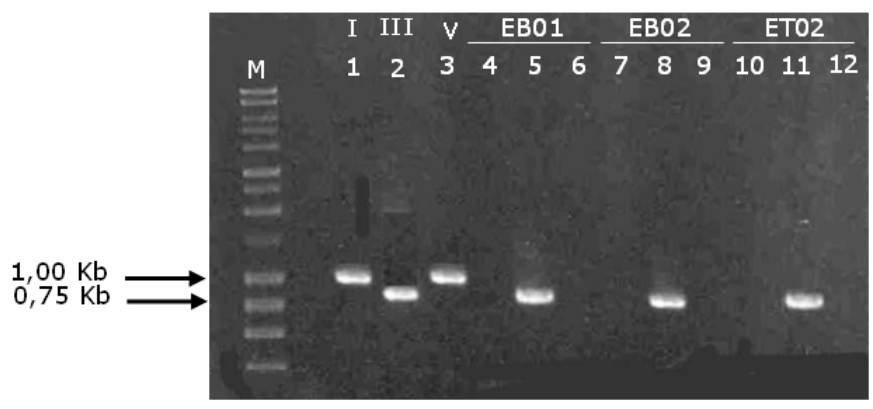

Figura 1. Amplificação do $16 \mathrm{~S}$ rDNA com iniciadores específicos. Nas colunas 5,8 e 11 bandas de $0,8 \mathrm{~kb}$, características para fitoplasmas do grupo 16SrIII, para os isolados das amostras EB01(berinjela), EB02 (berinjela) e ET02 (tomateiro). Na coluna 1, isolado proveniente de amostra sintomática de cana-de-açúcar, exibindo banda de $1,1 \mathrm{~Kb}$ para grupo $16 \mathrm{SrI}$; coluna 2, banda de isolado do grupo 16SrIII (chuchu) e coluna 3, isolado proveniente de crotalária, com banda de $1,1 \mathrm{~Kb}$ para grupo $16 \mathrm{SrV}$. Nas colunas 4, 7 e 10 ausência de bandas para grupo 16SrI e nas colunas 6, 9 e 12 ausência de bandas para grupo $16 \mathrm{SrV}$, nas amostras estudadas. $\mathrm{M}-$ marcador molecular $1 \mathrm{~kb}$ ladder.

\section{Identificação de fitoplasmas por análise de RFLP}

A análise de RFLP, conduzida com as enzimas de restrição AluI, MseI, HpaII, KpnI, RsaI e MboI, confirmou que os fitoplasmas detectados nas amostras EB01, EB02 e ET02 pertenciam ao grupo 16SrIII (Figura 2 e Figura 3). Estes resultados confirmaram a identificação feita com base no PCR usando iniciadores específicos para fitoplasmas do grupo16SrIII. Os padrões de restrição apresentados pelos fitoplasmas presentes nas três amostras foram indistinguíveis entre si, considerando-se individualmente cada uma das endonucleases usadas no teste. Os perfis eletroforéticos obtidos para os fitoplasmas detectados em tomateiro e berinjela, em relação a cada enzima de restrição, se enquadraram dentro dos padrões coletivos de RFLP adotados internacionalmente para a classificação de fitoplasmas representantes do grupo 16 SrIII.
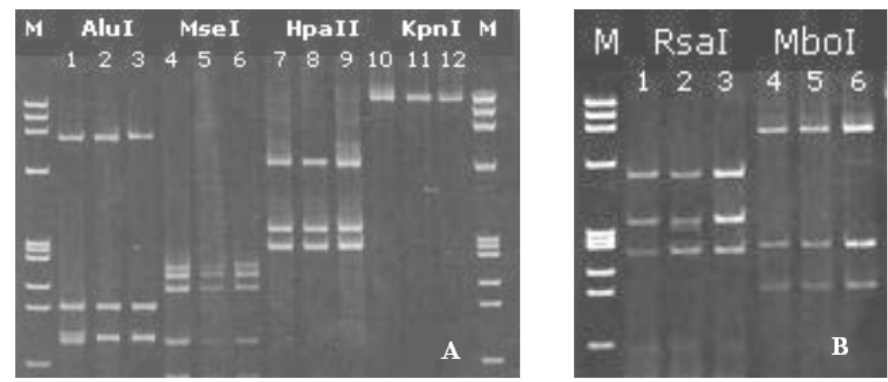

Figura 2- Análise de RFLP com as endonucleases AluI, MseI, HpaII, $K p n \mathrm{I}, R s a \mathrm{I}$ e $M b o \mathrm{I}$. Análise dos produtos de duplo PCR conduzido com os pares de oligonucleotídeos $\mathrm{R} 16 \mathrm{mF} 2 / \mathrm{mR} 1$ e R16 F2n/R2, utilizando DNA de plantas de berinjela (EB01/Piracicaba e EB02/Bragança) com sintomas de enfezamento. DNA de plantas de chuchu com superbrotamento, como representante padrão do grupo $16 \operatorname{SrIII}$ (A) Colunas 1, 4, 7 e 10: representante do grupo 16SrIII (chuchu). Colunas 2, 5, 8 e 11: amostras de EB01. Colunas 3, 6, 9 e 12: amostras de EB02. (B): Colunas 1 e 4: representante do grupo 16SrIII (chuchu). Colunas 2 e 5: amostras de EB01 e colunas 3 e 6: amostras de EB02. M - padrão de peso molecular ( X174RFHaeIII - 1353pb, 1078pb, 872pb, 603pb, 310pb, 271pb, 281pb, 234pb, 194pb, 118pb). 


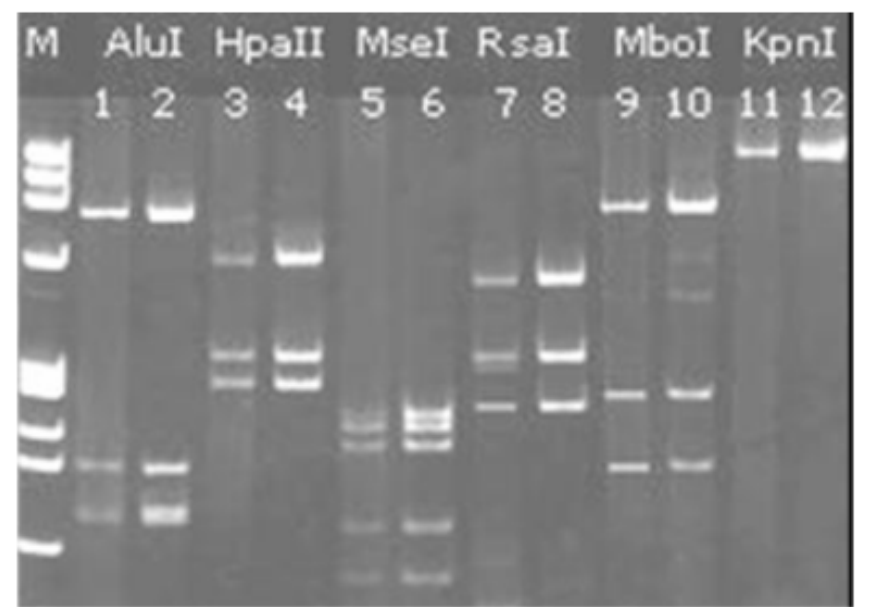

Figura 3 - Análise de RFLP com as endonucleases AluI, HpaII, MseI, RsaI, MboI e KpnI. Análise dos produtos de PCR duplo conduzido com os pares de oligonucleotídeos R16 mF2/mR1 e R16 F2n/R2, utilizando DNA de plantas de tomate (ET02/Bragança Paulista) com sintomas de enfezamento. DNA de plantas de chuchu com superbrotamento como representante padrão do grupo 16 SrIII. Colunas 1, 3, 5, 7, 9 e 11: amostras de ET02. Colunas 2, 4, 6, 8, 10 e 12: representante do grupo 16SrIII. M padrão de peso molecular ( $\phi$ X174RFHaeIII $-1353 \mathrm{pb}, 1078 \mathrm{pb}, 872 \mathrm{pb}$, $603 \mathrm{pb}, 310 \mathrm{pb}, 271 \mathrm{pb}, 281 \mathrm{pb}, 234 \mathrm{pb}, 194 \mathrm{pb}, 118 \mathrm{pb})$.

\section{Sequenciamento: similaridade de seqüência e análise putativa de sítios de restrição}

Os valores de similaridade das seqüências do gene $16 \mathrm{~S}$ rDNA encontrados para os fitoplasmas presentes nas amostras avaliadas foram superiores a 95\%, quando comparados com outros representantes do grupo $16 \mathrm{SrIII}$. Estes resultados permitiram classificar estes fitoplasmas como pertencentes a este grupo. As seqüências dos fragmentos clonados, correspondentes ao $16 \mathrm{~S}$ rDNA dos fitoplasmas encontrados nas plantas de tomate e berinjela, apresentaram índices de similaridade que variaram de 98 a 99\%, quando comparadas entre si, revelando o alto grau de similaridade genética existente entre estes fitoplasmas. Estes resultados confirmaram aqueles obtidos nos testes de PCR específico e também de RFLP, os quais também revelaram perfeita identidade entre os perfis eletroforéticos dos fitoplasmas estudados, tanto entre si como em relação aos fitoplasmas do grupo $16 \mathrm{SrIII}$.

As seqüências representativas dos fragmentos clonados, pertencentes aos fitoplasmas do enfezamento do tomateiro e da berinjela, foram submetidas à análise putativa de sítios de restrição e comparadas entre si (Figura 4). As observações mostraram correspondência entre os padrões de restrição visualizados na análise de RFLP e aqueles obtidos na análise putativa. Isto pode ser constatado comparando-se o número e o tamanho dos fragmentos genômicos gerados pela digestão do $16 \mathrm{~S}$ rDNA na análise de RFLP com aqueles observados no mapa de restrição. Ressalta-se que análise putativa de sítios de restrição não foi feita para a enzima MseI.

A identificação em nível molecular, através da análise do 16S rDNA dos fitoplasmas encontrados em tomateiro e berinjela, demonstrou que os mesmos eram membros do grupo 16SrIII, segundo os critérios atualmente adotados (18). O gene 16S rDNA é altamente conservado em procariotos e tem sido utilizado nos estudos moleculares que envolvem os fitoplasmas (7). Os recentes avanços no conhecimento dos fitoplasmas têm sido obtidos tomando-se por base justamente as

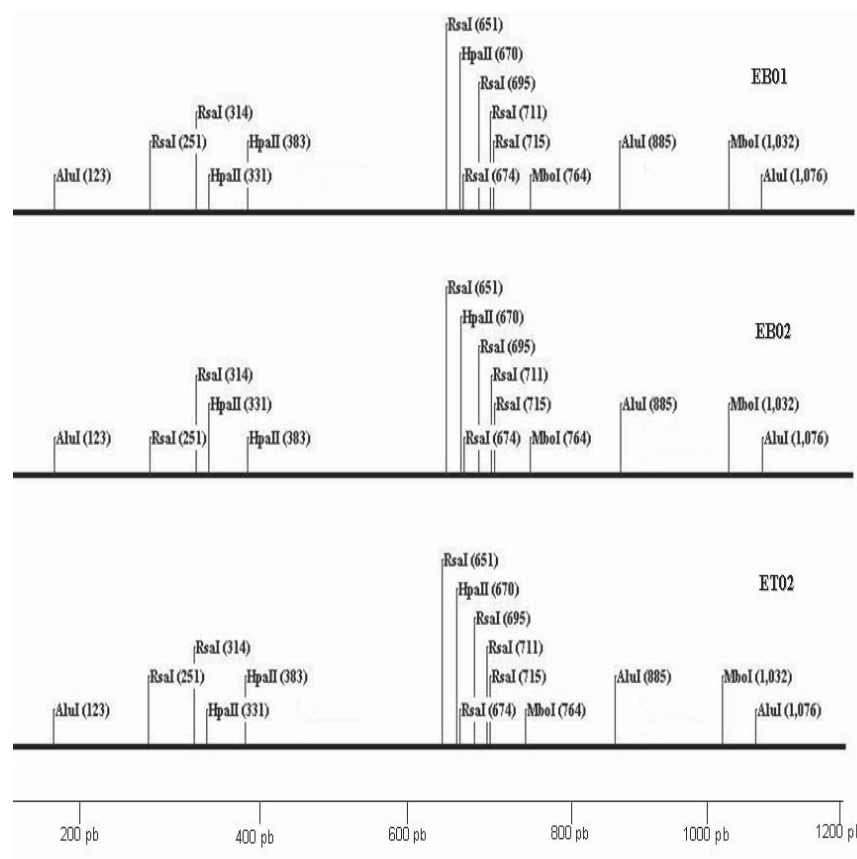

Figura 4 - Sítios de restrição presentes nas seqüências de nucleotídeos de fragmentos do $16 \mathrm{~S}$ rDNA representativos dos fitoplasmas detectados nas amostras EB01 (berinjela/Piracicaba) EB02 (berinjela/Bragança) e ET02 (tomate/Bragança). A barra contínua representa o tamanho do fragmento amplificado pelo par de oligonucleotídeo R16 F2n/R2 através de duplo PCR.

análises desse gene, no qual se fundamenta a atual classificação deste tipo de microrganismo (18).

Através da aplicação de técnicas moleculares como RFLP e sequenciamento genômico do $16 \mathrm{~S}$ rDNA, tem sido possível demonstrar a ocorrência de distintos fitoplasmas numa mesma espécie vegetal ou determinar a presença de fitoplasmas similares em espécies vegetais diversas (19). Os resultados do presente trabalho permitiram demonstrar que, com base na análise do gene 16S rDNA, existe alta similaridade genética entre os fitoplasmas do enfezamento da berinjela e do tomateiro, evidenciando que a doença possa estar sendo causada pelo mesmo fitoplasma. Este mesmo tipo de evidência foi demonstrada para os fitoplasmas associados à vassoura de bruxa ou irizado que ocorre no chuchuzeiro e no melão de São Caetano, sugerindo que esta espécie silvestre poderia atuar como reservatório (21). Evidências também foram encontradas para fitoplasmas de diversas daninhas presentes em cultivo de uva, as quais poderiam estar abrigando alguns fitoplasmas associados ao amarelo da videira (3).

Em relação à sintomatologia, é interessante observar que as plantas de tomate e berinjela apresentaram sintomas muito semelhantes, tais como, clorose foliar, desenvolvimento anormal do cálice, superbrotamento de ramos, porte reduzido da planta, encurtamento de entre-nós e folhas, frutos e flores de tamanho reduzido. A semelhança do quadro sintomatológico poderia ser considerada como mais uma evidência de que os enfezamentos estejam associados ao mesmo fitoplasma, pois ambas as espécies são botanicamente relacionadas, ou seja solanáceas, que poderiam reagir ao mesmo patógeno de forma similar quanto à expressão de sintomas. Fato idêntico ocorreu com plantas de chuchu e melão de São Caetano, pertencentes às cucurbitáceas, que exibiram 
sintomatologia semelhante para fitoplasmas considerados idênticos pela análise do $16 \mathrm{~S}$ rDNA (21). Ainda, em diversas espécies vegetais apresentando predominantemente sintomas de clorose foliar e superbrotamento de ramos foram identificados fitoplasmas pertencentes ao mesmo grupo de classificação, confirmando que fitoplasmas geneticamente relacionados, com base no 16S rDNA, podem causar o mesmo tipo de sintomas em espécies botânicas diferentes (27), assim como constatado neste trabalho para plantas de tomate e berinjela. Este tipo de informação pode contribuir para um maior entendimento sobre a epidemiologia da doença. No caso da vassoura de bruxa ou irizado do chuchuzeiro foi sugerido que o melão de São Caetano poderia atuar como hospedeiro alternativo do fitoplasma (21). No caso do tomateiro e berinjela também poderia estar ocorrendo a disseminação do agente patogênico de uma espécie vegetal para outra através de possíveis insetos comuns a ambas as espécies.

Os padrões coletivos de RFLP obtidos para o fitoplasma do tomateiro foram idênticos àqueles encontrados para o fitoplasma da berinjela, considerando-se as endonucleases AluI, MseI, HpaII, KpnI, RsaI e MboI, confirmando os resultados obtidos na identificação por PCR, com uso de iniciadores específicos. Com isto ficou claramente demonstrado que os fitoplasmas são representantes do grupo $16 \mathrm{SrIII}$. Os valores dos índices de similaridade de seqüências acima de $95 \%$ constatados entre os fitoplasmas estudados neste trabalho e representantes típicos de grupo16SrIII confirmaram, mais uma vez, que os fitoplasmas presentes em plantas sintomáticas de tomate e berinjela são afiliados a este grupo de classificação (21). Ainda, o índice de similaridade de $98-99 \%$ determinados para as seqüências correspondentes ao $16 \mathrm{~S}$ rDNA dos fitoplasmas encontrados em plantas sintomáticas de tomate e berinjela confirmaram o alto grau de identidade existente entre estes fitoplasmas. Uma vez que a análise putativa das seqüências de nucleotídeos do $16 \mathrm{~S}$ rDNA representativas destes fitoplasmas mostrou que os sítios de restrição são idênticos para as enzimas AluI, HpaII, KpnI, RsaI e $M b o I$, em concordância com a análise de RFLP, ficou evidente, uma vez mais, a similaridade entre os fitoplasmas do enfezamento do tomateiro e da berinjela.

Existem relatos mostrando a presença de um fitoplasma do grupo 16SrIII em plantas de tomate com enfezamento (cálice gigante), na Itália (25) e que um fitoplasma deste mesmo grupo foi identificado em plantas de berinjela com enfezamento, coletadas no Brasil (4). Estes relatos vêm ao encontro dos resultados obtidos no presente estudo, evidenciando que o mesmo fitoplasma pode estar associado ao enfezamento do tomateiro e da berinjela.

O grupo 16SrIII congrega uma grande parte dos fitoplasmas atualmente conhecidos no mundo (12), sendo associados a uma diversidade de doenças que ocorrem em uma gama enorme de plantas cultivadas, daninhas e silvestres (20). As evidências moleculares de que o fitoplasma associado ao enfezamento do tomateiro pode ser o mesmo fitoplasma associado ao enfezamento da berinjela, sendo pertencentes ao grupo 16SrIII, se constitui em mais uma contribuição ao conhecimento da ocorrência deste grupo de fitoplasmas em território brasileiro. Apesar da necessidade de testes de natureza biológica que possibilitem uma comprovação definitiva, a identificação dos fitoplasmas através do $16 \mathrm{~S}$ rDNA, no presente trabalho, apontou que um mesmo fitoplasma poderia estar envolvido na etiologia de uma doença potencialmente importante para duas espécies hortícolas de alto valor comercial na agricultura brasileira.

\section{REFERÊNCIAS BIBLIOGRÁFICAS}

1. Alma, A.; Davis, R.E.; Vibio, M.; Danielli, A.; Bosco, D.; Arzone, A.; Bertaccini, A. Mixed infection of grapevines in northern Italy by phytoplasmas including 16 S rRNA RFLP subgroup 16SrI - B strains previosly unreported in this host. Plant Disease, Saint Paul, v.80, n.8, p.418-421, 1996.

2. Anfoka, G.H.A.; Khalil, A.B.; Fattash, I. Detection and molecular characterization of a phytoplasma associated with big bud disease of tomatoes in Jordan. Journal of Phytopathology, Berlin, v.151, n.4, p.223-227, 2003.

3. Arzone, A ; Alma, A ; Bosco, D ; Patetta, A . MLO-infected weeds in the vineyards of north-wester Italy. Journal of Phytopathology, Berlin, v.143, n.4, p.257-260, 1995.

4. Barros, T.S.L. Caracterização molecular de Mollicutes fitopatogênicos no Brasil. 1995. $105 \mathrm{f}$. Tese (Doutorado em Biologia Molecular) - Departamento de Biologia Celular, Universidade de Brasília, Brasília.

5. Boiteux, L.S.; Lima, M.I.; Kitajima, E.W. Giant calyx: a disease of eggplant (Solanum melongena) associated with a mycoplasma-like organism in Brazil. Plant Pathology, Oxford, v.43, n.8, p.751-754, 1994.

6. Dale, J.L.; Smith, L.D. Mycoplasmalike bodies observed in tomato plants with big bud in Arkansas. Plant Disease Reporter, Saint Paul,v.59, n.8, p.455-458, 1975.

7. Davis, R.E. Fitoplasmas: fitopatógenos procarióticos sem parede celular, habitantes de floema e transmitidos por artrópodos. Revisão Anual de Patologia de Plantas, Passo Fundo, v.3, n.1, p.1-27, 1995.

8. Davis, R.E.; Jomantiene, R.; Dally, E.L.; Wolf, T.K. Phytoplasmas associated with grapevine yellows in Virginia belong to group 16SrI, subgroup A (tomato big bud phytoplasma subgroup), and group 16SrIII, new subgroup I. Vitis, Landau, v.37, n.2, p.131$137,1998$.

9. Granett, A.L.; Provvidenti, R. Tomato big bud in New York State. Plant Disease Reporter, Saint Paul, v.58, n.2, p.211$214,1974$.

10. Gundersen, D.E.; Lee, I.-M. Ultrasensitive detection of phytoplasmas by nested-PCR assays using two universal primer pairs Phytopathology Mediterranea, Bolonha, v.35, n.2, p.144$151,1996$.

11. Gundersen, D.E.; Lee, I.-M.; Rehner, S.A.; Davis, R.E.; Kingbury, D.T. Phylogeny of mycoplasmalike organisms (Phytoplasma): a basis for their classification. Journal of Bacteriology, Berlin, v.176, p.5244-5254, 1994.

12. Jomantiene, R.; Davis, R.E.; Valiunas, D.; Alminaite, A. New group 16SrIII phytoplasma lineages in Lithuania exhibit rRNA interoperon sequence heterogeneity. European Journal of Plant Pathology, Dordrecht, v.108, n.6, p.507-517, 2002.

13. Kirkpatrick, B.C. Mycoplasma-like organisms - Plant and invertebrate pathogens. In: Ballows, A.; Truper, H.; Dworkin, M.; Harder, W.; Schleifer, K. The prokaryotes. New York: Springer, 1992. v.4, p.4050-4067.

14. Kitajima , E.W.; Costa, A.S. Estruturas do tipo micoplasma no floema de tomateiro afetado pelo cálice gigante. Bragantia, Campinas, v.27, n.1, p.97-99, 1968.

15. Kitajima, E.W. Enfermidade de plantas associadas a organismos tipo micoplasma. Revisão Anual de Patologia de Plantas, Passo Fundo, v.2, n.1, p.153-174, 1994.

16. Lee, I.M; Hammond, R.W; Davis, R.E. Universal amplification and analysis of pathogen 16S rDNA for classification and identification of mycoplasmalike organisms. Phytopathology, Saint Paul, v.83, n.8., p.834-842, 1993.

17. Lee, I.M.; Gundersen-Rindal, D.E.; Hammond, R.W; Davis, R.E. Use of mycoplasmalike organism (MLO) group-specific oligonucleotide primers for nested PCR assay to detect mixed MLO infections in a single host plant. Phytopathology, Saint Paul, v.84, n.5, p.559-566, 1994.

18. Lee, I.M.; Gundersen-Rindal, D.E.; Davis, R.E., Bartoszik, I.M. Revised classification scheme of phytoplasma based on 
RFLP analyses of $16 \mathrm{~S}$ rDNA and ribosomal protein tgene sequences. International Journal of Systematic and Bacteriology, Ames, v.48, n.11, p.1153-1169, 1998.

19. Lee, I.M.; Davis, R.E.; Gundersen-Rindal, D.E. Phytoplasma: Phytopathogenic mollicutes. Annual Review of Microbiology, Palos Altos, v.54, n.1, p.221-255, 2000.

20. McCoy, R.E.; Caudwell, A.; Chang, C.J.; Yang, I.L.; Zhu, B.M.; Seemuller, E. Plant diseases associated with mycoplasma-like organisms. In: Whitcomb, R.F.; Tully, J.G. The Mycoplasmas. New York: Academic Press, 1989. v.5, p.545-640.

21. Montano, H.G.; Davis, R.E.; Dally, E.L.; Pimentel, J.P.; Brioso, P.S.T. Identification and phylogenetic analyses of a new phytoplasma from disease chayote in Brazil. Plant Disease, Saint Paul, v.84, n.4, p.429-436, 2000.

22. Montano, H.G.; Davis, R.E.; Dally, E.L.; Hogenhout, S.; Pimentel, J.P.; Brioso, P.S.T. 'Candidatus phytoplasma brasiliense', a new phytoplasma taxon associated with hibiscus witches'broom disease. International Journal of Systematic and Evolutionary Microbiology, Ames, v. 51, p.1109. 1118,2001 .

23. Ruegg, E.F.; Cousin, M.T. Ação da oxitetraciclina sobre o cálice gigante, moléstia causada por micoplasma. Arquivos do Instituto Biológico, São Paulo, v.41, n.1, p.39-46, 1974.

24. Salehi, M.; Izadpanah, K.; Taghizadeh, M. Herbaceous host range of lime witches' broom phytoplasma in Iran. Iranian Journal of Plant Pathology, Teerã, v.36, n.3-4, p.101-102, 2000 .

25. Serrone, P.D.; Merzachi, C.; Bragaloni, M.; Galeffi, P. Phytoplasma infection of tomato in central Italy. Phytopathology Mediterranea, Bologna, v.40, n.2, p.137-142, 2001.

26. Siddique, A .B.M.; Agrawal, G.K.; Alam, N.; Krishna Reddy, M. Electron microscopy and molecular characterization of phytoplasmas associated with little leaf disease of brinjal (Solanum melongena L.) and periwinkle (Catharanthus roseus) in Bangladesh. Journal of Phytopathology, Berlin, v.149, n.3, p.237-244, 2001.

27. Valiunas, D.; Alminaite, A ; Staniulis J.; Jomantiene, R; Davis, R.E. First report of aster yellows-related subgroup I-A phytoplasma strains in carrot, phlox, sea-lavander, aconitum and hyacynth in Lithuania. Plant Disease, Saint Paul, v.85, n.7, p.804, 2001.

28. Varma, J.P. Occurrence of tomato big bud like disease in Haryana. Science and Culture, Calcuta, v.45, n.3, p.205-207, 1979.

29. Zimmerman-Gries, S.; Klein, M. A tomato big bud-like disease of tomatoes in Israel and its association with mycoplasmalike organisms. Plant Disease. Reporter, Saint Paul, v.62, n.6, p.590-594, 1978 . 